\title{
Whole Exome Sequencing detects PYGM variants in two adults with McArdle disease
}

Thomas-Wilson, $A^{1^{*}}$, Dharmadhikari $A V^{1^{*}}$, Heymann, $\mathrm{JJ}^{1}$, Jobanputra, $\mathrm{V}^{1}$, DiMauro, $\mathrm{S}^{2}$, Hirano, $\mathrm{M}^{2}$, Naini, $A^{1 \#}$ and Ganapathi, $M^{1 \#}$

1. Department of Pathology and Cell Biology, Columbia University Irving Medical Center, New York, New York, USA

2. Department of Neurology, Columbia University Irving Medical Center, New York, New York, USA

joint first authors

\# Corresponding authors

Ali Naini, PhD

Professor

Department of Pathology and Cell Biology, Columbia University Irving Medical Center, New York, New York, USA abn2@cumc.columbia.edu

Phone: 212-305-1476

Mythily Ganapathi, PhD

Assistant Professor

Department of Pathology and Cell Biology, Columbia University Irving Medical Center, New York, New York, USA

Phone: 212-305-5378

mg3560@cumc.columbia.edu

Keywords: PYGM, McArdle, GSD type V, whole exome sequencing

Running Title: PYGM variants in McArdle disease 


\section{Abstract}

McArdle disease is a progressive and debilitating glycogen storage disease with typical onset in late childhood. Here we describe a former competitive athlete with early adult onset McArdle disease and a septuagenarian with a history of exercise-intolerance since adolescence who was evaluated for proximal muscle weakness. Exome sequencing identified bi-allelic variants in PYGM gene for both cases. The former athlete has the common, well-known pathogenic variant $\mathrm{p}$.(Arg50Ter) in trans with a novel missense variant, p.(Asp694Glu). The second individual has a previously described homozygous missense variant, p.(Arg771Gln). Here, we describe the clinical course, enzyme-testing results using muscle tissue and molecular findings for the individuals, and add to the knowledge of the genotypic spectrum of this disorder. 


\section{CASE PRESENTATION}

Individual 1 is a 28 year-old woman of Hispanic origin, who presented at the age of 25 years with episodic rhabdomyolysis, post-exercise myalgia, and myoglobinuria. Medical history is significant for hypothyroidism, migraine headaches, anxiety, and attention deficit hyperactivity disorder. Family history is negative for similarly affected individuals. She was a competitive cheerleader, gymnast, and snowboarder from age 13 to 24 years-old, but had muscle pain with exertion. At the age of 25 years, during an evening of drinking alcohol and dancing, she developed acute painful leg cramps and swelling as well as pigmenturia. She was admitted to a local hospital with markedly elevated creatine kinase (CK) of 107,000 U/L, which gradually declined over 10 days. Subsequently, she had more than 10 acute episodes of exertion-induced hyper-CKemia $>10,000 \mathrm{U} / \mathrm{L}$. Due to a combination of anxiety about recurrent exercise-induced myalgias and hyper-CKemia as well as inadequately treated hypothyroidism in her late 20's, she became deconditioned, fatigued, and felt subjectively weak with a normal neurological examination. With increased levothyroxine and a mild exercise program, her symptoms improved; however, she reports marked exercise-intolerance with activities such as moving the headboard of her bed, which provoked myalgias and CK elevation to 14,000 . She also has daily swelling and pain in her lower extremities after minimal exertion, followed by pain and swelling in her upper extremities on subsequent days.

Individual 2 is a 73 year-old man with history of muscle weakness, exercise-induced hyperCKemia and myoglobinuria. In addition, he had gout, hyperlipidemia, ischemic heart disease, and type 2 diabetes mellitus. The onset of the myopathic symptoms began at the age of 15 years, when he developed acute back pain when attempting to lift a heavy object. He subsequently, noted leg pain when he ran more than 300 meters, and reported chronic weakness. At age 61, after a traumatic fall, he had another episode of hyper-CKemia, and he developed transient renal insufficiency requiring dialysis. At age 72 years, he noted leg weakness, with difficulty rising from chairs, climbing stairs, and 
walking more than 15 steps due to leg "heaviness" without pain or cramps. At age 73 years, neurological examination revealed proximal limb weakness (deltoids 4+/5, biceps 4/5, and hip flexors 4/5). Family history includes a younger sister who has similar symptoms of periodic hemoglobinuria and exercise-intolerance. Family is of Eastern European Ashkenazi-Jewish ancestry.

Table 1 compares the clinical phenotypes seen in the two individuals (1\&2) using the Human Phenotype Ontology (HPO) terms typically associated with McArdle disease.

McArdle disease (Glycogen Storage Disease, type V; OMIM\#232600), caused by bi-allelic pathogenic variants in myophosphorylase (PYGM gene, MIM\# 608455) results from the inability to utilize glycogen to form glucose-1-phosphate during physical activity. It is characterized by exerciseinduced pain, cramps, rhabdomyolysis, markedly elevated creatine kinase, and a "second wind" phenomenon where affected individuals are able to return to physical activity after a brief period of rest (Martin, 2006). Most individuals with McArdle disease become symptomatic in late childhood or early teenage years, although milder late onset disease has been described (Pourmand, 1983; Petrou, 2015).

\section{TECHNICAL ANALYSIS}

Trio Whole Exome Sequencing for individual 1 and her parents (in 2016), and singleton proband only Whole Exome Sequencing for individual 2 (in 2018) was performed at the Laboratory of Personalized Genomic Medicine at Columbia University Medical Center on DNA extracted from peripheral blood mononuclear cells. Written consent was obtained, exome sequencing libraries were prepared from genomic DNA from the proband and the parents using Agilent SureSelectXT (Human All Exon v.5 + UTRs) capture kit according to the manufacturers' protocol. Paired-end sequencing was performed on the Illumina HiSeq 2500 platform. The sequence data were aligned to hg19 and annotated using Nextgene (version 2.3; Softgenetics, LLC. PA) software. Variant filtering and annotation were 
performed using an in-house developed pipeline and reviewed as part of the clinical workflow for constitutional clinical exome sequencing in the laboratory of Personalized Genomic Medicine at Columbia University Medical Center (Wang, 2016).

\section{RESULTS INTERPRETATION}

Previous laboratory results for individual 1 were negative for elevated levels of lactate and pyruvate, and positive for significantly elevated Creatine Kinase (resting CK; 5547.0 U/L, normal 40.0-308.0 $\mathrm{U} / \mathrm{L})$. CK was especially elevated during episodes of myoglobinuria $(107,000 \mathrm{U} / \mathrm{L})$ as described in the case presentation. Urine organic acids and plasma acylcarnitine profiles were unremarkable.

Glycolytic enzyme activity assay in the biopsied muscle revealed undetectable activity of myophosphorylase measured spectrophotometrically by nicotinamide-adenine dinucleotide phosphate reduction in the supernatant of muscle homogenate (mean \pm SD activity of 118 control samples: $24 \pm 7.4 \mu \mathrm{mol}$ glucose-l-phosphate liberated per minute per gram of fresh tissue). Activities of other enzymes in muscle were normal including phosphofructokinase, phosphoglycerate kinase, carnitine palmitoyltransferase, lactate dehydrogenase, phosphoglycerate mutase, and phosphorylase kinase (DiMauro, 1982).

Trio whole exome sequencing revealed bi-allelic variants in PYGM NM_005609.3: c.[148C>T];[2082C>A], NP_005600.1:p.[(Arg50Ter)];[(Asp694Glu)], (Table 2; ClinVar accession numbers: SCV001980710.1 and SCV001443154.1). These variants were confirmed by Sanger sequencing. The c.148C>T, p.(Arg50Ter) variant identified in this individual is one of the most common pathogenic variants described in PYGM (Martin, 2006), and has multiple independent pathogenic curations in ClinVar (VarlD:2298). cDNA studies have suggested that the c.148C>T, p.(Arg50Ter) variant is subject to nonsense mediated decay, as mature cDNA transcripts were not detected from this allele in individuals harboring the variant (Nogales-Gadea, 2008). The c.2082C>T, p.(Asp694Glu) is a rare missense variant in the C-terminal phosphorylase domain, downstream of the 
binding site for cofactor pyridoxal phosphate (Withers, 1981). In silico programs predict a damaging effect of this variant, on protein function (Table 2). It has not been previously reported in any affected individuals and is classified as likely pathogenic as per ACMG guidelines (Richards,2015; PM2 + PM3 + PP3 + PP4 (biochemical evidence)).

Previous laboratory testing for individual 2 is significant for abnormal resting serum Creatine Kinase: 900-3000 U/L. Proband's singleton whole exome sequencing revealed a homozygous, rare, missense variant in $\quad$ PYGM NM_005609.3:c.[2312G>A];[2312G>A], NP_005600.1:p.[(Arg771Gln)];[(Arg771Gln)], confirmed by Sanger sequencing (Table 2; ClinVar accession number: SCV001977607.1). In silico predictions for this missense variant are conflicting (Table 2). The variant alters the last nucleotide of the coding exon 18 and is also predicted to affect splicing (Trap Score: 0.989; dbscSNV: 0.9999). It has been previously reported in at least two affected individuals, once in trans with the pathogenic p.(Arg50Ter) PYGM variant (compound heterozygous, Nadaj-Pakleza, 2009), in another individual as a homozygous variant (Vieitez, 2011), and is classified as likely pathogenic as per ACMG guidelines (Richards, 2015; PM3_strong + PM2_supporting + PP2 + PP3 (consistent splicing predictions)). The individual's sister was not available for genetic testing.

\section{SUMMARY}

For McArdle disease, nonsense variants in PYGM account for $30-35 \%$ of disease-causing variants, and the most common pathogenic variant seen in affected individuals is a nonsense variant p.(Arg50Ter). An additional $50 \%$ of the pathogenic variants described in PYGM are missense variants, and they are distributed throughout the protein with no specific hotspot or domain associated with pathogenic variation (Nogales-Gadea et al., 2015). Furthermore, with few exceptions, most previously described pathogenic variants result in undetectable enzyme function and/or reduced transcript levels, presumably through RNA mediated decay or mRNA degradation (Nogales-Gadea, 
2008; García-Consuegra I, 2009). While there is no observed genotype-phenotype correlation associated with PYGM variants, identification of novel variants and associated clinical phenotypes is critical to expanding the body of knowledge of the genotypic and phenotypic spectrum of this disorder.

Here we report two cases of McArdle disease with varying ages-at-onset and severity, and wherein exome sequencing identified bi-allelic variants in PYGM gene. The first case is of a former competitive athlete who presented in young adulthood with recurrent episodes of exertional hyperCKemia, myalgia and myoglobinuria. This individuals' exceptional exercise capacity in youth with abrupt onset of debilitating exertional myalgias and hyper-CKemia at age 25 years-old highlights the uniqueness of this case. Enzyme studies showed undetectable myophosphorylase enzyme activity confirming a diagnosis of McArdle disease. One of the missense variants identified in this individual (c.2082C>T, (p.Asp694Glu)) has not been previously reported and thus expands the genotype spectrum of PYGM variants. The second individual had adolescent-onset recurrent exercise-induced hyper-CKemia and subjective weakness; with late-adult onset fixed proximal muscle weakness and carried the homozygous c.2312G>A, (p.Arg771Gln) PYGM variant. Clinical phenotype descriptions in previously reported individuals with this variant are limited, with normal muscle strength reported in one individual with McArdle disease in Nadaj-Pakleza, 2009. The early onset of weakness seen in the individual 2, is atypical for McArdle disease. In addition, individual 1 also had hypothyroidism while individual 2 had gout; those additional clinical features have been associated with McArdle disease in a large cohort study (Pizzamiglio, 2021).

\section{ADDITIONAL INFORMATION}

\section{Data Deposition and Access}

The variants were submitted to ClinVar (https://www.ncbi.nlm.nih.gov/clinvar/) and can be found under accession numbers: SCV001443154.1, SCV001977607.1, and SCV001980710.1. 


\section{Ethics Statement}

The study was approved by the institutional review board (IRB-AAAR1159, IRB-AAAA7683), and informed consent was obtained from the research subjects.

\section{Acknowledgements}

We thank the families for participating in this study.

\section{Funding Sources}

This research did not receive any specific grant from funding agencies in the public, commercial, or not-for-profit sectors.

\section{Author Contributions}

A.T.W, A.V.D., and M.G prepared the original draft. J.H. and M.H. oversaw patient care, and data collection. A.T.W, A.V.D, A.B.N., V.J. and M.G performed data analysis, and genetic interpretation. S.D., M.H., V.J., and A.B.N. assisted in critical revision of the manuscript. All coauthors read and approved the manuscript.

\section{REFRENCES}

Martín MA, Lucía A, Arenas J, Andreu AL. Glycogen Storage Disease Type V. In: Adam MP, Ardinger $\mathrm{HH}$, Pagon RA, Wallace SE, editors. GeneReviews ${ }^{\circledR}$ [Internet]. Seattle (WA): University of Washington, Seattle; 1993-2018. Available from: https://www.ncbi.nlm.nih.gov/books/NBK1344/

Pourmand R, Sanders DB, Corwin HM. Late-onset Mcardle's disease with unusual electromyographic findings. Arch Neurol. 1983;40(6):374-7.

Petrou P, Pantzaris M, Dionysiou M, Drousiotou A, Kyriakides T. Minimally symptomatic McArdle disease, expanding the genotype-phenotype spectrum. Muscle Nerve. 2015;52(5):891-5.

Wang Y, Lichter-Konecki U, Anyane-Yeboa K, Shaw JE, Lu JT, Östlund C et al. A mutation abolishing the ZMPSTE24 cleavage site in prelamin A causes a progeroid disorder. J Cell Sci. 2016;129(10):1975-80.

DiMauro S, Miranda AF, Olarte M, Friedman R, Hays AP. Muscle phosphoglycerate mutase deficiency. Neurology. 1982;32(6):584-91.

Nogales-Gadea G, Rubio J, Fernandez-Cadenas I, Garcia-Consuegra I, Lucia A, Cabello 
A et al. Expression of the muscle glycogen phosphorylase gene in individuals with McArdle disease: the role of nonsense-mediated mRNA decay. Hum Mutat. 2008;29(2):277-83.

Withers SG, Madsen NB, Sykes BD, Takagi M, Shimomura S, Fukui T. Evidence for direct phosphate-phosphate interaction between pyridoxal phosphate and substrate in the glycogen phosphorylase catalytic mechanism. J Biol Chem. 1981;256(21):10759-62.

Richards S, Aziz N, Bale S, Bick D, Das S, Gastier-Foster J, Grody WW, Hegde M, Lyon E, Spector E, Voelkerding K, Rehm HL; ACMG Laboratory Quality Assurance Committee. 2015. Standards and guidelines for the interpretation of sequence variants: a joint consensus recommendation of the American College of Medical Genetics and Genomics and the Association for Molecular Pathology. Genet Med. 17(5):405-424.

Nadaj-Pakleza AA, Vincitorio CM, Laforêt P, Eymard B, Dion E, Teijeira S et al. Permanent muscle weakness in McArdle disease. Muscle Nerve. 2009;40(3):350-57.

Vieitez I, Teijeira S, Fernandez JM, San Millan B, Miranda S, Ortolano S et al. Molecular and clinical study of McArdle's disease in a cohort of 123 European individuals. Identification of 20 novel mutations. Neuromuscul Disord. 2011;21(12):817-23.

Nogales-Gadea G, Brull A, Santalla A, Andreu AL, Arenas J, Martín MA et al. McArdle disease: Update of Reported Mutations and Polymorphisms in the PYGM Gene. Hum Mutat. 2015;36(7):66978.

García-Consuegra I, Rubio JC, Nogales-Gadea G, Bautista J, Jiménez S, Cabello A, et al. Novel mutations in individuals with McArdle disease by analysis of skeletal muscle mRNA. J Med Genet. 2009;46(3):198-202.

Pizzamiglio C, Mahroo AA, Khan KN, Patasin M, Quinlivan R. Phenotype and genotype of 197 British patients with McArdle disease: An observational single-centre study. J Inherit Metab Dis $2021 ; 44(6) 1409-1418$. 
Table 1: Comparison of clinical features seen in the two individuals with Human Phenotype Ontology (HPO) terms typically associated with McArdle disease

\begin{tabular}{|c|c|c|c|}
\hline HPO \# & Clinical feature & $\begin{array}{l}\text { Individual } \\
1\end{array}$ & $\begin{array}{l}\text { Individual } \\
2\end{array}$ \\
\hline HP:0003201 & Rhabdomyolysis & $\mathrm{Y}$ & $\mathrm{Y}$ \\
\hline HP:0002875 & Exertional dyspnea & NR & NR \\
\hline HP:0001919 & Acute kidney injury & NR & $\mathrm{Y}$ \\
\hline HP:0003546 & Exercise intolerance & NR & $\mathrm{Y}$ \\
\hline HP:0012378 & Fatigue & $\mathrm{Y}$ & $\mathrm{Y}$ \\
\hline HP:0008305 & Exercise-induced myoglobinuria & $\mathrm{Y}$ & $\mathrm{Y}$ \\
\hline HP:0002015 & Dysphagia & NR & NR \\
\hline HP:0003738 & Exercise-induced myalgia & $\mathrm{Y}$ & $\mathrm{Y}$ \\
\hline HP:0009045 & Exercise-induced rhabdomyolysis & $\mathrm{Y}$ & $\mathrm{Y}$ \\
\hline HP:0030234 & Highly elevated creatine kinase & $\mathrm{Y}$ & Y \\
\hline HP:0008967 & Exercise-induced muscle stiffness & $\mathrm{Y}$ & Y \\
\hline HP:0005216 & Impaired mastication & NR & $\mathrm{NR}$ \\
\hline HP:0003652 & Recurrent myoglobinuria & $\mathrm{Y}$ & $\mathrm{Y}$ \\
\hline HP:0040319 & Dark urine & NR & NR \\
\hline HP:0001649 & Tachycardia & NR & NR \\
\hline HP:0009073 & Progressive proximal muscle weakness & NR & Y \\
\hline HP:0003710 & Exercise-induced muscle cramps & NR & NR \\
\hline HP:0012622 & Chronic kidney disease & NR & NR \\
\hline HP:0030973 & Postexertional malaise & $\mathrm{Y}$ & $\mathrm{Y}$ \\
\hline HP:0003202 & Skeletal muscle atrophy & NR & NR \\
\hline HP:0009051 & Increased muscle glycogen content & NR & unk \\
\hline HP:0001639 & Hypertrophic cardiomyopathy & NR & NR \\
\hline \multicolumn{4}{|c|}{$\begin{array}{l}\text { Additional Clinical } \\
\text { Features }\end{array}$} \\
\hline HP:0000821 & Hypothyroidism* $^{*}$ & $\mathrm{Y}$ & $\mathrm{NR}$ \\
\hline HP:0001997 & Gout* $^{*}$ & NR & $\mathrm{Y}$ \\
\hline HP:0003077 & Hyperlipidemia & NR & $\mathrm{Y}$ \\
\hline HP:0001677 & Coronary artery disease & NR & $\mathrm{Y}$ \\
\hline HP:0005110 & Atrial fibrillation & NR & Y \\
\hline HP:0005978 & Type 2 diabetes mellitus & NR & $\mathrm{Y}$ \\
\hline
\end{tabular}

Y: Yes; NR: not reported; unk: unknown

${ }^{*}$ Recent association with McArdle disease reported in Pizzamiglio, 2021 
Table 2: Bi-allelic PYGM variants identified in individuals in this study, with relevant population frequencies, computational predictions and classification. The Refseq transcript used for annotation is NM_005609.3.

\begin{tabular}{|c|c|c|c|c|c|c|c|c|c|c|}
\hline \multirow{2}{*}{$\begin{array}{c}\text { Genomic } \\
\text { Coordinates } \\
\text { (hg19) }\end{array}$} & \multirow[b]{2}{*}{$\begin{array}{l}\text { Ref } \\
\text { Allele }\end{array}$} & \multirow{2}{*}{$\begin{array}{c}\text { Alt } \\
\text { Allele }\end{array}$} & \multirow{2}{*}{$\begin{array}{l}\text { HGVS } \\
\text { cDNA }\end{array}$} & \multirow{2}{*}{$\begin{array}{c}\text { HGVS } \\
\text { Protein } \\
\text { (inheritance) }\end{array}$} & \multirow{2}{*}{$\begin{array}{c}\text { Variant } \\
\text { Classification }\end{array}$} & \multirow{2}{*}{$\begin{array}{l}\text { gnomAD } \\
\text { (v2.1.1) } \\
\text { allele } \\
\text { frequency }\end{array}$} & \multicolumn{4}{|c|}{ Computational Predictions } \\
\hline & & & & & & & Provean & SIFT & $\begin{array}{l}\text { CADD } \\
\text { (v1.6) }\end{array}$ & REVEL \\
\hline $\begin{array}{c}\text { chr11:64517943 } \\
\text { (Individual 1) }\end{array}$ & G & $\mathrm{T}$ & c. $2082 \mathrm{C}>\mathrm{A}$ & $\begin{array}{c}\text { p.Asp694Glu } \\
\text { (Paternal) }\end{array}$ & $\begin{array}{c}\text { Likely } \\
\text { Pathogenic }\end{array}$ & not found & $\begin{array}{c}\text { Deleterious } \\
\text { (Score - } \\
3.86) \\
\end{array}$ & $\begin{array}{c}\text { Damaging } \\
\text { (Score } \\
0.000) \\
\end{array}$ & 14.29 & 0.707 \\
\hline $\begin{array}{l}\text { chr11:64527223 } \\
\text { (Individual 1) }\end{array}$ & G & A & c. $148 \mathrm{C}>\mathrm{T}$ & $\begin{array}{l}\text { p.Arg50Ter } \\
\text { (Maternal) }\end{array}$ & Pathogenic & $\begin{array}{c}1.4 \mathrm{e}-3, \text { no } \\
\text { homozygotes }\end{array}$ & $\mathrm{n} / \mathrm{a}$ & $\mathrm{n} / \mathrm{a}$ & 33 & $\mathrm{n} / \mathrm{a}$ \\
\hline $\begin{array}{l}\text { chr11:64514696 } \\
\text { (Individual 2) }\end{array}$ & $\mathrm{C}$ & $\mathrm{T}$ & c. $2312 \mathrm{G}>\mathrm{A}$ & p.Arg771GIn & $\begin{array}{c}\text { Likely } \\
\text { Pathogenic }\end{array}$ & $\begin{array}{c}7.1 \mathrm{e}-6, \text { no } \\
\text { homozygotes }\end{array}$ & $\begin{array}{l}\text { Deleterious } \\
\text { (Score - } \\
3.38)\end{array}$ & $\begin{array}{l}\text { Tolerated } \\
\text { (Score } \\
0.165)\end{array}$ & 35 & 0.913 \\
\hline
\end{tabular}

Variant allele fraction (VAF)

chr11:64517943-G-T, VAF: 0.42, 134/321 total reads;

chr11:64527223-G-A, VAF: $0.49,127 / 259$ total reads;

chr11:64514696-C-T, VAF: $1,43 / 43$ total reads 


\section{COLD SPRING HARBOR Molecular Case Studies}

\section{Whole Exome Sequencing detects PYGM variants in two adults with McArdle disease}

Amanda Thomas-Wilson, Avinash V Dharmadhikari, Jonas J Heymann, et al.

Cold Spring Harb Mol Case Stud published online January 12, 2022

Access the most recent version at doi: $10.1101 / \mathrm{mcs} . \mathrm{a} 006173$

Published online January 12, 2022 in advance of the full issue.

Accepted Peer-reviewed and accepted for publication but not copyedited or typeset; accepted Manuscript manuscript is likely to differ from the final, published version. Published onlineJanuary 12,2022 in advance of the full issue.

Creative This article is distributed under the terms of the

Commons http://creativecommons.org/licenses/by-nc/4.0/, which permits reuse and

License redistribution, except for commercial purposes, provided that the original author and source are credited.

Email Alerting Receive free email alerts when new articles cite this article - sign up in the box at the Service top right corner of the article or click here. 